\title{
Social Stigma and Mental Health among Rural-to-Urban Migrants in China: A Conceptual Framework and Future Research Needs
}

\author{
Xiaoming Li, PhD., Wayne State University School of Medicine Pediatric Prevention \\ Research Center, Email: xiaoli@med.wayne.edu \\ Bonita Stanton, M.D., Wayne State University School of Medicine Pediatric Prevention \\ Research Center \\ Xiaoyi Fang, Ph.D., Beijing Normal University Institute of Developmental Psychology \\ Danhua Lin, Ph.D., Beijing Normal University Institute of Developmental Psychology
}

\begin{abstract}
There are over 100 million individuals in China who have migrated from rural villages to urban areas for jobs or better lives without permanent urban residency (i.e., "rural-to-urban migrants"). Our preliminary data from ongoing research among rural-to-urban migrants in China suggest that the migrant population is strongly stigmatized. Moreover, it appears that substantial numbers of these migrants experience mental health symptoms (e.g., depression, anxiety, hostility, social isolation). While the population potentially affected is substantial (more than $9 \%$ of the entire population or about one-quarter of the rural labour force in mainland China) and our data seem to indicate that the issue is pervasive in this population, there is limited literature on the topic in China or elsewhere. Therefore, in the current article, we utilize secondary data from public resources (i.e., scientific literature, governmental publications, public media) and our own qualitative data to explore the issues of stigmatization and mental health, to propose a conceptual model for studying the association between the stigmatization and mental health among this population, and to identify some future needs of research in this area.
\end{abstract}

\section{Rural-to-Urban Migration in China: "Floating Population"}

The term "rural-to-urban migrants" used in this article refers to those individuals who move from rural areas to urban areas for jobs and better lives without obtaining permanent urban residency (China National Bureau of Statistics [CNBS] 2001). In China, these individuals also are often referred to as the mobile population, peasant-workers, temporary migrants, rural migrants, migrant workers, or floating population (Zhang 2001; Lin et al. 2005). 
Migration from rural to urban areas was restricted in China through the household registration ("hukou") system for almost a quarter century until economic reform took place in the late 1970s. Under the "hukou" system, everyone was assigned to a particular place of residence and the Chinese population was officially divided into urban residents and rural residents. Rural residents were prohibited from moving into the cities. The rural economic reform with the introduction of the Household Contract Responsibility System in 1979 resulted in a rapid growth in agricultural output (i.e., an increase of 56\% from 1979 to 1985) and a large surplus of agricultural labourers, estimated at 300 million excess farmers as of 2000 (Wakabayashi 1990). Concurrently, rapid economic growth in urban areas had increased the income disparity between urban and rural areas to a historically high level. Rural incomes were 55\% of urban incomes in 1983, but decreased to 31\% in 2005 (\$402 in rural areas and \$1,296 in urban areas) (CNBS 2006a). This increasing income gap has provided a strong incentive to rural residents to migrate to urban areas in search of better lives. Consequently, hundreds of thousands of Chinese peasants are transient, displaced from their native villages to cities, forming the "floating population," one of the largest internal migrations in recent history in China (Seeborg et al. 2000). Most of these migrants come from the poor rural areas of the interior provinces with weak industrial bases. Because of existing legal restrictions on employment and housing in urban areas (Zhou 1997), this movement has largely been in the form of temporary migration (i.e., $80 \%$ ), rather than permanent relocation (Zhou 1999).

The most recent population statistics released by the Chinese government indicated that there were 147.35 million migrants in China as of November 2005 (CNBS 2006b). However, no information was available for further analysis of their demographic characteristics. According to the China 2000 Census Data (the most current national database with demographic statistics) (CNBS 2001), there were 121 million migrants in China in 2000. Among those migrants, 88.4 million (73\%) were from rural villages and 32.7 million (27\%) were from townships or small cities. In terms of destinations, 78.65 million (65\%) migrated within the same provinces and 42.42 million (35\%) migrated to different provinces. The general geographic trend of migration was from the middle and western parts of China to the eastern and coastal areas. Nationwide, $13 \%$ of all rural families have one or more family members who migrated to urban areas (CNBS 2001). Recent ethnographic studies among several migrant communities in Beijing (Zhang 2001) have found that most of the Chinese rural-to-urban migrations are in the form of chain migrations based on kinship ties and native-place networks.

With support from National Institute of Mental Health (NIMH), we conducted an HIV/STD intervention feasibility study among young rural-to-urban migrants in two major Chinese metropolitan areas (Beijing and Nanjing) from 2001-2005 (Li et al. 2004; Li et al. 2006). Although the NIMH project was not designed to study the stigmatization and mental health issues associated with a migratory lifestyle in China, our preliminary data suggest that the migrant population is strongly stigmatized. Moreover, it appears that substantial numbers of these migrants experience mental health symptoms (e.g., depression, anxiety, hostility, social isolation). While the population potentially affected is substantial (more than $9 \%$ of the entire population or one-quarter of the rural labour force in mainland China) and our data seem to indicate that the issue is pervasive in this population, there is limited literature on the topic in China or elsewhere. Therefore, in the current article, we will utilize secondary data from public resources (e.g., China Census Data, scientific literature, governmental publications, public media) and our own qualitative data to explore the issues of stigmatization and mental health, to propose a conceptual model for studying the association between the stigmatization and mental health among this population, and to identify some future needs of research in this area.

\section{Data Resources}

The data we analyzed in the current article include the China 2000 Census Data, the secondary data from scientific literature, governmental publication, public media and the qualitative data we collected in Beijing and Nanjing, China. The China 2000 Census Data were collected from all 
Chinese citizens who resided in China from November 1 to November 20, 2000 (CNBS 2001). The qualitative data were collected in Beijing, China's capital, and Nanjing, the capital city of Jiangsu Province in eastern China. Beijing covers 16,800 square kilometres with a population of 13.82 million. The Beijing municipal government has jurisdiction over eight urban districts, eight suburban districts and two rural counties. There are about three million rural-to-urban migrants (70\% male and 30\% female) in Beijing (Beijing Municipal Information Office [BMIO] 2002). Among the migrants in Beijing, about $25 \%$ are employed by construction companies, $20 \%$ are selfemployed and $40 \%$ work as temporary workers (hourly waged or short-term contracted) (BMIO 2002). Nanjing, which is about 1,200 kilometres from Beijing, has jurisdiction over six urban districts, four suburban districts and five rural counties with a total area of 6,516 square kilometres and a total population of 5.3 million. The rural-to-urban migrant population in the Nanjing metropolitan area is estimated at 800,000 .

During the qualitative phase of the NIMH research project, we interviewed a purposeful sample of 90 rural-to-urban migrants (50 in Beijing and 40 in Nanjing). The recruitment and data collection procedure of the qualitative study has been described elsewhere (Hong et al. 2006a; Hong et al. 2006b). Briefly, the migrants were recruited from their work places, labour markets or homes through a network sampling. Local community leaders (both formal and informal) in the migrant settlements served as facilitators for the recruitment process. All interviewers were trained graduate students and junior faculty members in the field of psychology and education in Beijing Normal University and Nanjing University. Individual interviews were conducted in private places established as convenient for the interviewees. Each participant was assured of his/her confidentiality in the study, and an informed consent form was signed before the interview started. Each interview took about 60 to 90 minutes; all interviews were audio-taped and transcribed. The Institutional Review Boards at West Virginia University, Beijing Normal University and Nanjing University approved the study protocol. The demographic characteristics of the 90 migrants are shown in Table 1.

\section{Demographic Characteristics of Rural-to-Urban Migrants}

\section{Age}

The majority of the migrants are young, most commonly aged 20-29, with the next highest concentrations in the adjoining age group, 15-19 (Zhou 1999). The China 1990 census data indicated that $50.7 \%$ of the migrants were $15-29$ years of age; the China $19991 \%$ population survey indicated $71 \%$ of the migrants were between 15-34 years of age (Wan 1995). The Chinese Academy of Social Sciences recently estimated that over $80 \%$ of the rural-to-urban migrants are less than 35 years of age (Wu and Zhou 1996). China 2000 Census Data indicated a median age of 32.8 years, younger than either urban permanent residents (39.6 years) or rural permanent residents (34 years) (CNBS 2001).

\section{Gender}

There were more males than females in the early waves of rural-to-urban migration (i.e., pre-1990). According to a 1986 survey of 70,216 migrants (Tie 1999), $74 \%$ were males and $26 \%$ were females (Tie 1999). However, there has been an increase in female migration since the early 1990s. The 1995 China 1\% Population Survey showed that $57.6 \%$ of the migrants were male, which was consistent with the China 1990 Census Data (55.5\% of the migrants were male) (Wan 1995). Both 1990 and 1995 data indicated that there were more females than males in the 15-19 age group (Wan 1995). Gender distribution of migrants varies greatly by occupation, with more males being in construction and more females in domestic service and entertainment industries (Qian 1986).

\section{Education}

In general migrants tend to be more educated than rural residents who do not migrate but less educated than urban residents. China 1990 Census Data revealed that the average years of education was 6.27 for rural residents, 7.44 for migrants and 8.86 for urban residents (Wan 1995). China 2000 
Census Data indicate that $10.3 \%$ of the adult migrants (15 years of age and older) were illiterate, 24.2\% finished elementary school, 52.2\% finished middle school, and 13.3\% finished high school. There is a substantial gender difference in the level of education, as $50 \%$ of the female migrants only finished elementary school (CNBS 2001).

Table 1. Demographic characteristics of 90 migrant participants

$\begin{array}{lll}\text { Variables } & \mathbf{N} & \%\end{array}$

Age (years, mean=24.54)

\begin{tabular}{|l|c|c|}
\hline $15-19$ & 3 & $3 \%$ \\
\hline $20-24$ & 49 & $54 \%$ \\
\hline $25-29$ & 31 & $34 \%$ \\
\hline $30-37$ & 7 & $8 \%$ \\
\hline Gender & 44 & \\
\hline Male & 46 & $51 \%$ \\
\hline Female & & \multicolumn{2}{|c|}{} \\
\hline
\end{tabular}

Marital Status

\begin{tabular}{|l|c|c|}
\hline Single & 69 & $77 \%$ \\
\hline Married & 19 & $21 \%$ \\
\hline Divorced & 2 & $2 \%$ \\
\hline
\end{tabular}

Education Completed

\begin{tabular}{|l|c|c|}
\hline Primary education not completed & 3 & $3 \%$ \\
\hline Primary school & 11 & $12 \%$ \\
\hline Junior high & 36 & $40 \%$ \\
\hline High school & 9 & $10 \%$ \\
\hline Post-secondary school & 30 & $33 \%$ \\
\hline
\end{tabular}

Age of First Time Working in Cities

\begin{tabular}{|l|c|c|}
\hline Less than 19 & 53 & $59 \%$ \\
\hline $20-24$ & 25 & $28 \%$ \\
\hline $25-34$ & 3 & $3 \%$ \\
\hline Nor reported & 11 & $12 \%$ \\
\hline
\end{tabular}

\section{Years in Cities}

\begin{tabular}{|c|c|c|}
\hline $1-4$ & 21 & $24 \%$ \\
\hline $5-8$ & 17 & $19 \%$ \\
\hline$>=9$ & 14 & $16 \%$ \\
\hline
\end{tabular}

${ }^{1}$ Including vocational school and three-year college 


\section{Marital Status}

China 2000 Census Data indicate that $20.3 \%$ of adult migrants (15 years of age and older) were single (17.6\% and $19.4 \%$ for urban and rural counterparts, respectively). Among those who migrated to other provinces, $29.2 \%$ were single (CNBS 2001). A study among migrant construction workers (98\% male) in Beijing revealed that 39\% were single, $51 \%$ were married and $10 \%$ were either widowed or divorced (Du 1986).

\section{Cultural and Social Context of Migrants' Lives in Cities}

\section{Migrant Community in the City}

In recent years, numerous migrant communities (or "migrant villages") have been established in almost every Chinese city. Some of the communities have gone through development, demolition and eventual reconstruction (Zhang 2001). Most of these migrant communities were organized based on the migrants' common place of origin, while some were organized around urban occupation (e.g., construction, textile manufacturers). For example, there are at least eight migrant communities in the four central urban districts in Beijing: "Wali" and "Laiguangyin" communities in the Chaoyang district; "Dongshang" and "Zhongguan" communities in the Haidian district; "Babaoshan" and "Pingguoyuang" communities in the Shijingshan district; and "Majiapu" and "Dahongmen" in the Fengtai district. Each of these communities has at least 10,000 migrant residents. The Zhejiang village (demolished in 1996 and rebuilt in 1998), for example, alone had about 100,000 migrants in 1995 (Zhang 2001). The migrant communities in Nanjing are mainly scattered outside the metropolitan area and located along the major highways. Most of the migrant communities in Nanjing are also named with the migrants' common place of origin such as "Auhui village," and "Xuzhou village" (Zhou 1997). In addition to these self-enclosed migrant communities, many employers in labour-intensive sectors (e.g., construction, entertainment establishments, beauty salons) often provide migrant workers with dormitory-type housing as a means to attract and/or manage migrant workers.

\section{Housing}

Most of the migrants are housed in densely populated areas under poor sanitary conditions (Wan 1995; Duan and Zhou 2001; Zeng 1997; Huang 2000). During our interview in Beijing, one 21year-old male described his domicile: more than 30 people slept in bunk beds in a single room in an unfinished underground storehouse without a window, showers or air ventilation. They were only allowed to take a shower or bath at a nearby building once per week.

\section{Duration of Stay}

A 1996 study in Beijing indicated that 24\% of the migrants stayed in Beijing for three months or less; $21 \%$ stayed from three to six months, $31 \%$ stayed from 6 to 12 months, $16 \%$ stayed from one to three years, and 7\% stayed in Beijing more than three years (World Bank 1997). A 1997 study found that $22 \%$ of migrants in Beijing stayed one to three years and $18 \%$ stayed more than three years (Zeng 1997). There has been a general trend for a longer stay, particularly among young migrants. A 2000 survey in the Jiangsu Province found that the average stay of young female migrants (mean age 20.8 years old) was 23 months (Huang 2000).

\section{Employment}

One-third (33.4\%) of the migrants were considered to be "self-employed," $20.2 \%$ worked for individual or private business, and $11.8 \%$ had their own business (i.e., had at least one employee) (CNBS 2001). Only about 13\% of migrants worked for state or local government-owned business, collective business, corporations, foreign joint-adventure, or other large business, compared to $74 \%$ of urban residents with employment in the same category. Among the "self-employed," most of them 
were working in jobs that urban residents generally find inferior or distasteful (e.g., street food/goods vendors, bicycle or shoe repair, garbage and recyclable collection).

\section{Challenges in City}

Worldwide, transitions are difficult; this experience was no different for rural-to-urban migrants in China. Despite their hopes that the city would bring fortunes or opportunities not possible in their villages, many had experiences similar to that of a young man who recalled: "The first time I came to Beijing was 1999; I was only $17 . .$. It was really hard. I only had money for taking the bus and all I could afford to buy for food was one big cookie. And the permit checking was very strict in Beijing. I didn't want to beg for help, and so I slept in a big tree." Even those fortunate enough to find work often discovered that they were being taken advantage of by their employers - and with no recourse: "I worked for half a year and earned only 500 Yuan [approximately US \$62]. No more! I was tricked by the boss!"

For migrants, the opportunity to find employment that included housing was highly desirable, although often the housing conditions themselves were not optimal: "We cannot care much about personal hygiene. We have too many people. There are 50 [migrants] in our company. We live in a big room. And we plan to have more people soon. The plan is to have 80 people and we will live in two rooms. It is actually a big underground storage space." The challenges in the cities also included unfulfilled physical and emotional needs. One 27-year-old female migrant, who was in Nanjing with her husband, described her sex life in the city: "We live in the company's dorm; we don't have money to rent an apartment. So we basically don't have any sex life. During the four years of working in Nanjing, we almost had no sex, except when we went home during the holidays."

Despite these personal hardships and the initial financial disappointments, many of the migrants grew to embrace this new lifestyle, with its economic rewards, conveniences and faster pace. One young man observed: "Working in here, you get yourself fed, and you get money. Working home - to be honest, you got to be so angry - and it was too tiring. If you work at home [on the farm], you need to pay this, pay that, this fee, that fee, all kinds of taxes. You have nothing left for living."

\section{Mental Health among Rural Migrants in China}

There is limited data available on the mental health status of rural-to-urban migrants in China. Through a search of electronic databases including MEDLINE, PsycINFO and Sociological Abstract (CSA), we have only located one English article in this area (Shen et al. 1998). Shen and colleagues examined the mental health symptoms among 371 (166 males and 205 females) migrant workers in Shenzhen, China. They found that migrant workers (mean age 22.90 \pm 2.67 years) had poorer mental health status, as measured by SCL-90, than their non-migrant counterparts and general population in China (i.e., the Chinese norms on SCL-90). In their stepwise regression model, several psychosocial factors were found to be predictive of mental health symptoms. These factors include neuroticism, psychological pressure, income, home sickness, marital or love problems, extroversion and introversion, living conditions and social status (Shen et al. 1998). Our qualitative interviews revealed that some migrants in cities demonstrated hostility, social isolation and poor social adjustment. For example, most migrants acknowledged that they did not have any friends in Beijing except knowing some fellow villagers. One 23-year-old girl (a karaoke and dance club attendant who had been in a city for over six years) described her feeling towards people in [name of the city]: "After staying in [name of the city] for so many years, I feel that [name of the city] is so-so; nothing is particularly good. [Name of the city] people are not good. I do not know how to describe them but ... women are like shrews and men like thieves ..." One 20 -year-old male (express delivery worker) described his trouble with sleeping when he came to Beijing. He often could not go to sleep the whole night and often had nightmares: "I cannot describe the situation in my dream. It was a nightmare by all means, but I do not know what kind of nightmare. I soaked wet [sic] when I woke up ..."A 20-year-old male repairman described the instance where he drank eight bottles of beer one time and said: "For people like us, when we felt bad, smoking and drinking are the only way to divert ourselves [from bad feelings]." 


\section{Stigma and Stigmatization: Conceptual Framework}

Stigma has been described by U.S. sociologist Erving Goffman as a quality that significantly discredits an individual in the eyes of others (Goffman 1963). Stigma has important consequences for the way in which individuals come to see themselves. Although there is great variation in conceptualizing stigma (Stafford and Scott 1986), stigma is generally considered to be an attribute used to separate affected individuals from the normalized social order (Gilmore and Somerville 1994). The separation implies a process of devaluation and discrimination against the stigmatized group (Gilmore and Somerville 1994). Other authors have found there is an important distinction to be made between "felt" and "enacted" stigma (Jacoby 1994). Felt stigma arises from the real or imagined stigmatizing response of others, while enacted stigma refers to actual acts of discrimination (Jacoby 1994; Scombler and Hopkins 1986). Some authors choose to refer to discrimination as "enacted stigma" (Malcolm et al. 1998), while "felt enactment" is composed of the "actions or treatment based on stigma and directed toward the stigmatized" (Bunting 1996). Because the concepts of stigmatization and discrimination are closely linked, they are frequently referred to together in this article.

\section{Enacted Stigma}

Gilmore and Somerville (1994) have described four main features of any stigmatizing response: the problem that initiates the reaction; the identification of the group or individual to be targeted; the assessment of stigma to this individual or group; and the development of the stigmatizing response. Link and Phelan (2001) proposed a conceptual framework of stigma. In their model, stigma is a process during which five interrelated components converge. The five components include "Labelling" (people identify and label human differences); "Stereotyping" (link labelled individuals to undesirable characteristics or negative stereotypes); "Separation" (place labelled individuals in distinct categories, separating "us" from "them"); "Status loss" (labelled individuals experience devaluation that leads to unequal outcomes); and "Discrimination" (systematic disapproval, rejection and exclusion towards labelled individuals). According to the model, stigmatization is "wholly contingent on access to social, economic and political power that allows the identification of differences, the construction of stereotypes, the separation of labelled persons into distinct categories and the full execution of disapproval, rejection, exclusion and discrimination" (Link and Phelan 2001: 3). Enacted stigmatization is linked to power and cultural beliefs that dominate society and in the norms and values that govern much of everyday life. It creates, and in turn is reinforced by, social inequality. It causes labelled individuals to be devalued and shamed, and others to feel that they are superior. In addition, as a cyclical process, much stigmatization against labelled individuals not only builds upon but also reinforces earlier negative stereotyping.

\section{Felt Stigma}

Felt stigma refers to feelings that labelled individuals experience when they internalize the negative responses and reactions of others. It may have an important role to play in affecting the mental health and "policing" the behaviour of those stigmatized. Felt stigma is harmful, both in itself - it can lead to depression, feelings of worthlessness, shame, guilt, low self-esteem, low self-efficacy, withdrawal, and isolation of stigmatized individuals - and because negative thoughts often lead individuals to do or not to do things that harm others or deny them services or entitlements.

\section{Examples of Enacted Stigmatization against Migrant Workers in China}

\section{"Stereotyping"}

Rural migrants have been distinctly "labelled" and negatively "stereotyped." The common images of rural migrants created by the media are of people who are poor, dirty, ignorant and prone to violence (Huai 2001). In addition, rural migrants have been frequently blamed for the increasing crime rates and social instability in the cities. It was reported by Chinese authorities that "migrant crime" (a distinct crime category used recently by the Chinese justice system and the media to refer to crimes 
committed by migrants) accounts for the majority of the crimes in the society. According to the media, migrant crimes accounted for $60 \%$ of the total crimes in Beijing in 2001 (Shi 2002). Migrant crimes were reportedly as high as $70 \%$ of the total crime in some suburban areas in Beijing. In one southern province where drug trafficking is prevalent, one government agency publicly claimed that "all drug trafficking in the province were committed by floating population" (Guan 2002). While some scholars in China have questioned the use of "migrant crime" as a distinct crime category in government reports (parallel to burglary, rape, homicide, etc.) and the way "migrant crime" statistics were calculated by the law enforcement agencies, such reporting is still a common practice by the government and media in China. Rural migrants (as a whole group) were also blamed in large part for the HIV/STD epidemic in China. The Chinese Minister of Health publicly exclaimed in 1996 (with no sero-prevalence statistics on which to base his assertion) that "the 80-120 million people in the 'floating population' which moves throughout the country in search of work carry the HIV virus into China's population centres" (Wu and Zhou 1996).

\section{"Separation"}

The migrants are regarded by governmental officials and local residents as a drain on urban public resources and a threat to the well-being of urban society, despite the fact that the cheap labour and services provided by rural migrants are in high demand in the cities. The following excerpts are from an official document in Beijing: "Outsiders are a necessity for the modernization of the city, since modern cities benefit from the labour services provided by the outsider labour force to their basic industries and essential service provisions; but the cities also have to expend a certain amount of social capital on them. Because the government has a direct responsibility for the development of the social economy and increasing the quality of life for the city residents, both the government and city residents hope that they can get maximum benefit from the labour services provided by outsider workers while at the same time minimizing the social capital expended [on them]. The basic means is to increase the costs of migration, in order to control the overall number of outsiders ..." (Beijing Committee of the Democratic League 1999). Such beliefs have been incorporated into some societal policies and institutions. For example, migrants have to pay more than local residents for many of their daily essentials such as housing, utilities, education and transportation. In some central urban districts in Beijing, migrants were not permitted to purchase an apartment unit. In one district of Beijing, for a house rented to or occupied by migrants, the occupant was charged 82 yuan per watt of electricity compared to .42 yuan for local residents. Since 1998, Beijing public transportation authorities have prohibited non-Beijing residents from purchasing a monthly discount bus pass (Wu 2001).

\section{"Status Loss"}

According to China's existing laws, a person living in a city without a city "hukou" is required to have a "temporary residency registration" with the public safety agencies. However, most of the rural-to-urban migrants do not have such a license because of the cumbersome and costly procedures required to obtain such a license (Zhou 1997). The government considers the "unregistered" rural-to-urban migration as "illegal" and is attempting to control the migration by a number of restrictive and coercive actions in the cities. There are periodic campaigns for "cleaning-up" (illegal migrants) in many urban areas. The campaigns consist of arresting and deporting migrants back to their home villages. In the first six months of 2002, Beijing municipal government claimed that they had arrested and deported 180,000 "illegal" rural migrants and promised to increase such actions in the future (Wu 2001). During our interviews in Beijing, a 20 -year-old male described his experience and his feelings about actions taken by the local government:

Beijing's joint public safety force ... is not fair in checking our registration or permits! ... It was the most difficult situation to handle. If you have your registration card, but do not have a temporary residency permit, they will arrest you and fine you. They can tear up your permit and then say you do not have it and have you pay a fine. Also about deportation, I really do not 
understand it ... it was said because of the social order in Beijing, but it was attitudes towards outsiders ... Deportation will cost [migrants] five or six hundred yuan ... when they deport you, they put you in the van they used to transport prisoners and treat you like a criminal ... how can they do that to me? I am this country's citizen ...! I do not know whether [the government] has ever thought about our workers. Hope they will think a little bit more for the workers. I was deported last time. I came from Jiangxi and I had required permits, but they still deported me. I came from Jiangxi, but they sent me to Changsha [a city in a different province]!

\section{"Discrimination"}

Rural migrants have to overcome a number of barriers in seeking legitimate employment. First, rural migrants are required to pay as many as 12 different fees to local government and obtain up to six governmental registrations or permits for employment (Krieger 1999). These documents include: temporary residency permit, certification for migration, permit for employment, health certificate, certification of marital status and compliance with family planning policy. It normally takes migrants at least three months and costs them from 500 to 1,000 Yuan (about one month salary for most of migrants working at city) to obtain all required documents for employment. Most of these permits/registrations have to be renewed annually. The second barrier is government restrictions on employing migrants in certain major industries and corporations. For example, Beijing municipal government published annual guidelines permitting or restricting certain occupations to employ migrants. In 1999, the list contained at least 36 "restricting" occupations that include telephone operators, store salesclerk, bus driver and conductor, box-office clerk, warehouse clerk and hotel attendants (Wu 2001). The migrants were only allowed to work on jobs related to the handling of corpses, sewage, chemical wastes and construction. In addition to the official restrictions, local businesses also set up preferences to disqualify migrants in their recruitment. For example, almost all the job advertisements in Beijing's local newspapers list "Beijing residency" as an essential requirement. Even most manual jobs open to migrants (such as those in the job market) require "high school education."

\section{"Unfair treatment"}

The economic situation and legal status of migrants give them limited options for appropriate employment; many of them are forced to accept jobs with unfair terms and low pay. Some of them have to work "illegally" in informal sectors for minimal salary and substandard working conditions without basic employment rights or job security. Because of the lack of government regulation protecting migrants' rights, many migrants have to work overtime, either as part of their job contract, or to achieve economic survival. Some employers purposely hire migrants without required permits or retain migrants' permits in their own custody, so the migrants have no way to leave and have to endure whatever the employers offer to them. Some employers (particularly those in construction) will promise migrants certain wages, but will only pay the migrants a small allowance (about onetenth of their wage) monthly and withhold the rest ("back wage") (Huai 2001; Wu 2001). If migrants decide to leave before the project is accomplished, they may lose their entire back wage. A recent homicide case involving a migrant worker who killed four people over 5,000 yuan (about \$625) in wage arrears was much publicized in China (Liu 2005). The migrant worker had worked over a year for a building contractor before quitting. However, the contractor refused to pay him the withheld wages, which totalled about 5,000 yuan. The migrant worker chose to end the long confrontational dispute by stabbing the contractor and three others to death. According to a report published by the Beijing-based Legal Aid and Research Center for Youth, employers throughout the country owe migrant workers more than 100 billion yuan (\$12.38 billion) in withheld wages (Liu 2005).

\section{"Exclusion" (Education opportunity for children)}

Members of the migrant population are often denied many of the basic privileges enjoyed by urban residents, such as access to subsidized housing, subsidized medical care and schooling for their 
children. Compulsory education in China, which was implemented in the late 1980s, consists of nine years of schooling including six years of elementary school (Grades 1-6) and three years of middle school (Grades 7-9). However, under China's hukou system, only the local government where a child's hukou is registered is responsible for providing the child with compulsory education (Wan 1995). (It was estimated that 1.8 million school-aged children who migrated to urban areas with their parents were not able to access their right to "compulsory" education (Human Rights in China [HRIC] 2002). Because of increasing social concern about this problem, the Chinese government has posted a number of regulations since 1996 allowing the enrolment of migrant children in schools and encouraging communities to set up privately owned schools for migrant children. However, the majority of migrant children are still denied the opportunity for quality education in urban areas either because of their parents' "illegal status" or because their parents cannot afford the additional fees (usually five to six times higher than what urban residents pay) the school charges for their enrolment (Wu 2001). A survey indicated that only 12.5\% of migrant children 6 through 14 years of age in Beijing attend public schools (Shi 2002).

\section{Stigmatization and Mental Health}

Several social and psychological theories developed in the United States have hypothesized that the experience of stigmatization may result in negative psychological and physiological changes among stigmatized individuals and lead to greater risk for depressive distress and anxiety, and to higher rates of some psychiatric disorders (Mays and Cochran 2001; Krieger 1999). Societal Reaction Theory (Link and Cullen 1990) or Labelling Theory (Link and Cullen 1992), for example, directly addresses the effects of stigma and negative social attitudes on stigmatized individuals. According to these theories, stigma may lead to labelling and negative societal reaction. As a consequence, stigmatized individuals develop adaptive and maladaptive responses that may include psychopathology (Link and Cullen 1990). Symbolic Interaction Theory and Social Comparison Theory (Stryker and Statham 1985) also hypothesize that negative attitudes and actions from others lead to negative self-perceptions (Rosenberg 1979) and adverse mental health outcomes (Crocker and Major 1989; Jones et al. 1984). Consistent with the Theories of Distributive Justice and Equity (Adams 1965; Walster et al. 1978), Williams and colleague (Williams and Williams-Morris 2000) contend that a higher level of unfair treatment in day-to-day life resulting from a socially stigmatized status can lead to the induction of psychological distress.

A growing body of research on social inequality and mental health outcomes in the United States has provided empirical support for these theories. For example, a study among gay men in New York demonstrated that stressors related to their stigmatization (e.g., internalized homophobia, expectation of rejection and discrimination, and actual prejudice events) were positively associated with distress and independently contributed to a number of mental health symptoms (Meyer 1995). Link and colleagues also indicated that stigma and labelling are related to adverse effects on selfesteem among the mentally ill (Link and Cullen 1990; Link 1987; Link et al. 1987). Williams and colleagues, in the Detroit Area Study (DAS), have also suggested an association between perceived discrimination (both chronic and acute) and mental health, depression and psychological distress (Ren et al. 1999; Williams et al. 1997). Kessler and colleagues, employing data from National Survey of Midlife Development in the United States (MIDUS) (Kessler et al. 1997), demonstrated the associations of perceived discrimination with mental health. Also using MIDUS data, a study found that perceived discrimination was positively associated with both harmful effects on quality of life and psychiatric morbidity among homosexual and bisexual individuals (Mays and Cochran 2001). Based on these empirical results, several investigators concluded that both the psychological and physiological correlates and consequences of discrimination are similar to those of other psychosocial stressors (Dion et al. 1992; Thompson 1996; Al-Issa 1997; Kessler et al. 1999).

\section{Effects of Migration and Stigmatization}

The global literature has suggested that migration is associated with a greater risk for poor health 
in general and mental illness in particular (Williams 1989; Williams and Berry 1991). This may be due to situational and psychosocial factors such as the impact of socio-cultural patterns of the migration, their economic transitions, reduced availability and accessibility of heath services, and the difficulty of the recipient community healthcare systems to cope with the traditions and practices of the migrants.

Based on the observation that migrants often experience strong feelings of loneliness, alienation, de-socialization, low-esteem and an inability to cultivate or sustain social relationships, the Theory of Social Isolation suggests that situational and psychological isolation (e.g., separation from one's network of social interaction and their original culture and value) precipitates mental illness and that subjective interpretation of isolation may predispose migrants to mental health symptoms (Weinberg 1966). The theory also suggests that a severe limitation of contact and communication with the recipient society and community causes the migrants great stress in the performance of their social roles and might directly or indirectly contribute to the onset of mental illness (Kuo 1976).

In early research on migration and mental health, Kantor (1969) pointed out that migration involves changes in the environment, which implies adjustments on the part of the migrants, and these adjustments may be reflected in improved or worsened mental health. Two existing theories, the Theory of Cultural Shock (TCS) (Oberg 1960) and the Theory of Culture Change (TCC) (Papajohn and Spiegal 1971) emphasize the effect of the acculturation or adjustment process on migrants' mental health. The TCS proposes that migrants entering a society substantially different from their native community will find it difficult to adjust to the "hosting" community because of the value conflicts and feelings of personal inefficacy. The TCC hypothesizes that among migrants undergoing acculturation, adaptation of competing cultural values of the hosting community and deviation from (or devaluation of) their native culture will result in a disruption and a shift in the cognitive and affective modes of behaviour and will have a disruptive effect on their psychological functioning.

The Theory of Goal-Striving Stress (TGSS) proposes the discrepancy between a migrant's premigratory aspirations and post-migration achievements (i.e., goal-striving stress or unfulfilled aspiration) is the source of mental distress (Williams and Berry 1991). The TGSS contrasts with other theories in that psychological stress due to other stressors in the migration process (e.g., cultural shock) may be mediated by a lower degree of goal-striving stress (Parker et al. 1969). Studies among Vietnamese immigrants in the United States have found that a high level of goal-striving stress results in elevated symptom levels (McKelvery et al. 1993; McKelvery and Webb 1996).

In addition to those psychosocial stressors associated with the migration process, migrants are also frequently discriminated against because of the stereotypes associated with migratory status (e.g., "outsiders"). As discussed in the preceding section, such stigmatization causes anxiety and distress - factors that are known to contribute to mental and physical illness. One of the questions of interest to this article is whether perceived stigmatization has an additional effect to the routine situational and psychosocial stressors associated with migration on the psychopathology among migrants. Several investigators have tried to answer this question among other types of migration (such as immigrants, refugees). For example, studies (Kuo 1995; Noh et al. 1999) found that Southeast Asian refugees in Canada who experienced racial discrimination had higher depression levels than those who had not perceived any discrimination. Also studying immigrants (including Chinese immigrants) in Canada, researchers suggested an association between ethnic discrimination and higher levels of stress, anxiety, depression and hostility (Dion et al. 1992; Dion and Barn 1975; Dion and Giordana 1990; Miritsuga and Sue 1983). While these findings are very informative in guiding the design and development of the hypotheses in this article, direct application of any specific finding to Chinese migrant workers is limited for at least two reasons. First, existing studies have been conducted largely among migrations that were in the form of permanent resettlements such as transculture or transcountry immigrants, war refugees or internal migrants in North American and European countries (Kuo 1995; Noh et al. 1999; Dion and Barn 1975; Dion and Giordano 1990; Miritsuga and Sue 1983; Sluzki 1986; Pernice and Brook 1996). Second, most of the migration in earlier studies was driven not only by economic reasons but also by cultural, political, ecological or religious reasons. 


\section{Impact of Stigmatization on Chinese Migrants: A Conceptual Model}

While there have been numerous instances of stigmatization and discrimination against rural migrants, there is very limited systematic scientific enquiry exploring the forms and sources of the stigma and the impact of the stigmatization on mental health among this vulnerable population. Based on our observation of the situation in China, we will propose a conceptual model and some hypotheses in this article. These hypotheses and conceptual model will inform and guide future study to explore the association between stigmatization and mental health among this population.

While there has been some theoretical speculation and empirical evidence that stigmatization is a chronic stressor that relates to psychopathology, few studies have addressed how perceptions of stigmatization are directly or indirectly related to psychopathology. Diaz and colleagues (2001) tested a theoretical model between social discrimination (e.g., experiences of homophobia, poverty and racism) and mental health (symptoms of psychological distress) among gay and bisexual Latino men. In the model, they hypothesized that social discrimination influenced mental health through its effect on social isolation and low self-esteem. They also hypothesized that the impact of social discrimination would be mediated by a number of resiliency factors (e.g., community involvement, family acceptance, life satisfaction, role models) that diminished social isolation and increased selfesteem. The data from 912 gay and bisexual Latino men in three US cities generally confirmed the model (Diaz et al. 2001). Similarly, in a study among 3,012 adults of Mexican origin in California, Finch and colleagues found that perceived discrimination was directly related to depression and that the effect was moderated through a number of psychosocial factors (e.g., level of acculturation and gender) (Finch et al. 2000). Dion and colleagues (1992) also suggested that discrimination has a direct link to depression and operates indirectly through stress and diminished self-efficacy. Building upon this previous research, we propose to adapt the model employed by Diaz and colleagues (2001) to conceptualize the relationship among stigma, migration and mental health (Figure 1). We anticipate that status-based stigmatization serves as a stressor for psychopathology and has both direct and indirect effects on the mental health status of migrants with the following hypotheses.

Figure 1. A conceptual framework of relationship among stigma, migration and mental health

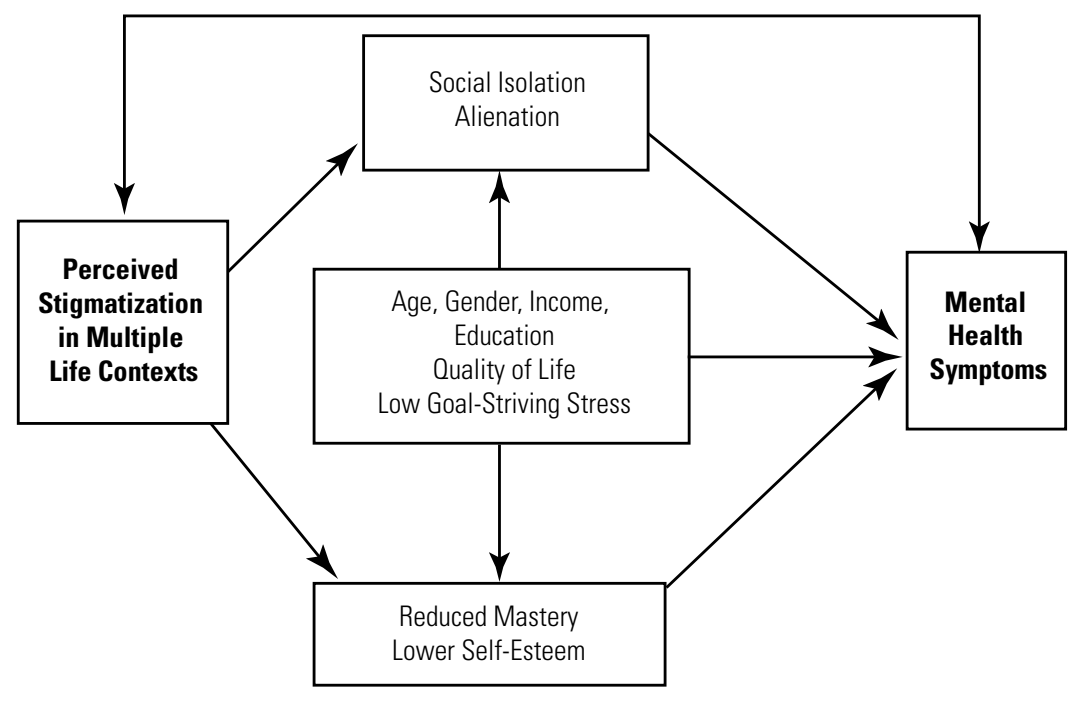

First, we hypothesize that stigmatization will exacerbate the social isolation associated with migration. The Theory of Social Isolation postulates that social isolation was the most tumultuous and destructive experience associated with migration. Stigmatization may further set up psychosocial 
barriers for migrants to enter a new social network in recipient communities and intensify feelings of loneliness, alienation and desocialization among migrants. In addition, in a highly stigmatizing environment, migrants may withdraw from society as a means of self-protection.

Second, we hypothesize that stigmatization will contribute to poorer psychosocial adjustment in the urban environment, and the poor adjustment in turn will be associated with increased mental health symptoms. While parts of the TCS (Oberg 1960) and the TCC (Papajohn and Spiegal 1971) offer conflicting views (Kuo 1976) and findings from studies testing these two theories have been inconsistent (Pernice and Brook 1996; Beiser 1988), both theories do imply that migrants' self-efficacy (sense of mastery) and ability to adjust, psychologically and socially, to the "hosting" community, will impact their mental health. Many authors have suggested a relationship between perceptions of mastery and self-esteem and psychological well-being (Pearlin et al. 1981; Rosenfield 1997). Therefore, we hypothesize that the stigmatization will affect migrants' mental health by damaging their sense of mastery and self-esteem and reducing their ability to adjust to the urban environment.

Third, we hypothesize that a number of demographic and psychosocial factors (such as age, gender, income, education, goal-striving stress, pre-migratory awareness) will mediate the impact of stigma on mental health symptoms. According to a number of conceptual models of stigma (Gilmore and Somerville 1994; Jacoby 1994; Scombler and Hopkins 1986), the stigmatized individuals need to internalize the "enacted" stigma for the stigma to affect their psychological well-being. Despite stigma and discrimination, most migrant workers in China and their families were financially better off than they had been pre-migration, so their economic gains may mitigate the effects of stigmatization and they may choose not to internalize "enacted" stigma. During our qualitative interviews, most migrants complained about the stigmatization and discrimination in Beijing. However, many of them also expressed pride and happiness when they mentioned the support they provided to their parents or family by sending their savings home. In addition, pre-migratory awareness of stigmatization may also mediate the effects of post-migration stigmatization experience. Our preliminary data indicate that most of the migrants were fully aware of the hardship and discrimination they were going to face in the urban area before they arrived (yet they keep coming), so they might be psychologically prepared to cope with the stigma and discrimination.

With support from the National Institute of Health Fogarty International Center and the National Institute of Mental Health, we are currently collecting data from representative samples of rural-to-urban migrant workers in Beijing to test this conceptual model. Although our data will evaluate the effect of social stigma on the mental health of migrant workers in Beijing, China, the findings and research methodology developed could well apply to migrant populations in other regions and countries.

\section{Future Research Needs}

While we hypothesize that there will be different layers (e.g., institutional, cultural, societal, community) and different forms (e.g., prejudice, rejection, discrimination) of stigmatization against ruralto-urban migration in China, many questions need to be answered. For example, what are the structures and social, cultural or economic roots of this stigma? Status-related stigma can appear in a variety of forms, at a variety of levels and in a variety of contexts. Mapping these forms will be the first step towards being able to identify their determinants. In addition, we should explore the association of migrant stigma with broader existing inequalities, injustices and denial of migrants' realization of human rights and fundamental freedoms.

A major methodological issue in stigma research has been the measurement of stigma and stigmatization (Williams and Williams-Morris 2000; Harvey 2001). The DAS study (Williams et al. 1997) and the MIDUS study (Kessler et al. 1997) have provided a comprehensive conceptual framework and a useful approach in measuring stigmatization and discrimination.

In the DAS study, a scale of major experiences of discrimination was used to measure unfair treatment due to race/ethnicity. The scale asks questions in the generic context of unfair treatment 
without reference to race or ethnicity. The scale distinguishes major episodic experiences from chronic, ongoing, day-to-day experiences of unfair treatment. This scale also distinguishes past year (recent) experiences of discrimination from earlier lifetime episodes. An additional follow-up question to each endorsed discrimination item ascertained the main reason for unfair treatment. Respondents were allowed to select from a list that included ethnicity, gender, race, age, religion, physical appearance, sexual orientation and income level/social class. Thus, unfair treatment attributed to race/ethnicity can be distinguished from discrimination that was attributed to other social bases.

A revised version of the scale was used in the MIDUS survey. The measure included 11 items of "lifetime occurrences of discriminatory experience" in the areas of education (e.g., denied scholarship), work (e.g., not hired for a job), receiving financial and other serves (e.g., denied a bank loan) and experience with social hostility (e.g., forced out from neighbourhood by neighbours). Respondents were also asked to indicate how frequently (never, rarely, sometimes, often) they experienced each of nine types of discriminatory behaviours on a day-to-day basis (e.g., "people act as if they think you are not as good as they are"; "people act as if they are afraid of you"). Those respondents who indicated any occurrence of discrimination were asked to select one or more of 10 possible causal reasons for the discrimination (e.g., age, sex, race, ethnicity, physical appearance characteristics). The outcomes of stigmatization and discrimination were assessed using two questions regarding the extent (not at all, a little, some, or a lot) to which discrimination has "interfered with having a full and productive life" and "had made life harder." The approaches and format employed in the MIDUS survey may be culturally adapted in future study to assess the stigma and stigmatization among rural migrants in China and other nations or regions.

It is worthwhile to note that most of the assessment approaches in the literature only measure individual level "perception" of stigmatization rather than directly assess institutional or societal stigmatization. Previous research has argued that the effects of institutional and societal stigmatization will most likely be captured in individual perceptions and experiences and in the measures of socioeconomic status (Finch et al. 2000).

It is also clear from the preceding sections that the process of stigmatization can have a wide range of adverse consequences on the well-being of the stigmatized individual. The question then becomes, how best to quantify those consequences. Mental health outcomes, variously characterized in literature as psychological distress, depression, self-esteem, anxiety and psychopathology, have been consistently documented and are therefore a specific focus of this article. However, to asses mental health symptoms alone may not be sufficient, given the observed impact of stigmatization on physical health and social interactions. Therefore, to more fully explore and quantify the outcomes of stigmatization, a broad-based assessment of overall functioning and well-being will add breadth to the measurement and increase our odds of detecting the true impact of migration-related stigmatization. Measures such as quality of life will offer such an assessment by including indices of physical, mental and social well-being.

It has been estimated that the rural-to-urban migration process will accelerate at an annual increase of 8.5 million migrants in the coming decade as modernization and industrialization proceeds in China (Wu 2001). The stigmatization associated with migration will have a negative impact on different levels of society. The identification and development of appropriate interventions to address social stigma require both a good understanding and preliminary data regarding the forms, contexts and outcomes of the social stigma and the mechanisms by which the social stigma affect mental health among the migrant population. Future studies are needed in this regard to enrich our knowledge.

The migrant population has attracted considerable attention from the government, media and society at large. However, there is virtually no systematic scientific effort to study the issues of stigma and mental health among this large and increasing population. Future efforts are needed to develop the local infrastructure and capacity of mental health research among the local professionals. Efforts are needed to bridge the gap between advocacy, policy-making and research in the field by applying a participatory approach that involves many societal sectors (e.g., academic, governmental, communities and migrants) through the research process. 
There are mass movements of economic migrants (e.g., rural-to-urban) in many developing countries, particularly in Asian countries (Haour-Knipe et al. 1999). This economic-driven migration is occurring extensively in Western Europe and the United States as well. In particular, Latino immigration to the United States for economic reasons is very large (Finch et al. 2000) and presently very visible due to proposed legislation (Weisman 2006). These migrations will pose challenges to the moral, security, family and disease prevention infrastructures in each nation. Although little research has been conducted to address stigma and mental health issues among these migratory populations, there is certainly an urgent need for addressing stigma and mental health promotion among migrants and to devise effective, affordable and culturally appropriate stigma reduction interventions targeting these populations. Lessons we are learning from the China experience could benefit relevant research on the mental health impact of migrants for economic purposes to the United States and other regions/countries. Future studies, particularly with cross-culturally validated assessment instruments, will benefit other regions and nations in social stigma reduction and mental heath promotion among migratory populations.

\section{Acknowledgement}

This study is supported by NIH grants R01MH064878 and R21TW006375. The authors wish to thank our other participating investigators and their assistants at the Beijing Normal University Institute of Developmental Psychology and the Nanjing University Institute of Mental Health for their assistance in data collection.

\section{References}

Adams, J.S. 1965. "Inequity in Social Exchange." In L. Berkowitz, ed., Advances in Experimental Social Psychology Vol. 2 (pp. 267-99). New York: Academic Press.

Al-Issa, I. 1997. The Psychology of Prejudice and Discrimination. In I. Al-Issa and M. Tousignant, eds., Ethnicity, Immigration, and Psychopathology (pp. 17-32). New York: Plenum Press.

Beijing Committee of the Democratic League. 1999 (February 9). Service Using the Capital Educational Resources to Increase the Educational Level and Quality of the Children of Outsiders in the Capital (Proposal Prepared for the 2nd meeting of the 9th Beijing People's Political Consultative Conference). Beijing: Beijing Committee of the Democratic League.

Beijing Municipal Information Office [BMIO]. 2002. Migrant Population in Beijing. Beijing: BMIO.

Beiser, M. 1988. "Influences of Time, Ethnicity and Attachment on Depression in Southeast Asian Refugees." American Journal of Psychiatry 145(1): 46-51.

Bunting, S. 1996. "Sources of Stigma Associated with Women and HIV." Advanced Nursing Science 19(2): 64-73.

China National Bureau of Statistics (CNBS). 2001. Characteristics of Chinese Rural Migrants: 2000 (News Release, September 10, 2001 - Updated March 31, 2002). Beijing: Author. .

China National Bureau of Statistics (CNBS). 2006a (February 28). China 2005 Social Economics and Social Development Statistics. Beijing: CNBS.

China National Bureau of Statistics (CNBS) 2006b (March 16). Communiqué on Major Data of 1\% National Population Sample Survey in 2005. Beijing: CNBS.

Crocker, J. and B. Major. 1989. "Social Stigma and Self-esteem: The Self-protective Properties of Stigma. Psychological Review 96(4): 608-30.

Diaz, R.M., G. Ayla, E. Bein, J. Henne and B.V. Marin. 2001. “The Impact of Homophobia, Poverty, and Racism on the Mental Health of Gay and Bisexual Latino Men: Findings from 3 US Cities.” American Journal of Public Health 91: 927-32.

Dion, K.L. and B.M. Barn. 1975. “The Phenomenology of Being a Target of Prejudice.” Journal of Personality and Social Psychology 32: 944-50.

Dion, K.L., K.K. Dion and A.W.P. Pak. 1992. "Personality-based Hardiness as a Buffer for Discriminationrelated Stress in Members of Toronto's Chinese Community.” Canadian Journal of Behavioral Science 24(4): 517-36.

Dion, K.L. and C. Giordano. 1990. "Ethnicity and Sex as Correlates of Depression Symptoms in a Canadian University Sample.” The International Journal of Social Psychiatry 36: 30-41. 
Du, W. 1986. "A Discussion of the Problem of the Floating Population in the City Districts of Beijing." Population \& Economics 1: 12-4.

Duan, C. and H. Zhou. 2001. "An Analysis on the Situation of Floating Children and Juveniles in Beijing." Population \& Economics 124: 5-11.

Finch, B.K., B. Kolody and W.A. Vega. 2000. "Perceived Discrimination and Depression among Mexicanorigin Adults in California." Journal of Health and Social Behavior 41(3): 295-313.

Gilmore, N. and M.A. Somerville. 1994. "Stigmatization, Scapegoating, and Discrimination in Sexually Transmitted Diseases, Overcoming “Them” and "Us.” Social Science \& Medicine 39: 1339-58.

Goffman, E. 1963. Stigma: Notes on the Management of Spoiled Identity. Englewood Cliffs, N.J.: Prentice Hall.

Guan, W.L. 2002. Chinese, Do You Salute Peasant Workers? Retrieved March 18, 2002. <http://www.clibrary. com>.

Haour-Knipe, M., M. Leshabar and G. Lwihula. 1999. "Interventions for Workers Away from their Families." In L. Gibney, R.J. DiClemente and S.H. Vermund, eds., Preventing HIV in Developing Countries. Biomedical and Behavioral Approaches (pp. 257-82). New York: Plenum.

Harvey, R.D. 2001. "Individual Differences in the Phenomenological Impact of Social Stigma." Journal of Social Psychology 141(2): 174-89.

Hong, Y., B. Stanton, X. Li, H. Yang, D. Lin, X. Fang, J. Wang and R. Mao. 2006a. "Rural-to-urban Migrants and the HIV Epidemic in China: A Qualitative Study." AIDS and Behavior 19: 1-10.

Hong, Y., X. Li, B. Stanton, D. Lin, X. Fang, R. Mao and J. Wang. 2006b. "Too Costly to be Ill: Access to Health Care and Health Seeking Behaviors among Rural-to-urban Migrants in China." World Health and Population 4: 19-31.

Huai, X. 2001. Peasants' Cry (No. 9). (Article originally published in Chinese Youth Newspaper, 1998.) <http// www.nongyou.org>.

Huang, R. and L. Yang. 2000. "Studies on the Basic Status of the Floating Population in China." Northwest Population 4: 47-51.

Huang, Y. 2000. "Marital Status and Attitudes Towards Marriage Among Female Migrants in Jiangsu." South China Population 15(2): 39-43.

Human Rights in China (HRIC). 2002 (May 8). Shutting Out the Poorest: Discrimination Against the Most Disadvantaged Migrant Children in City Schools. New York: HRIC.

Jacoby, A. 1994. "Felt Versus Enacted Stigma, A Concept Revisited." Social Science \& Medicine 38: 269-74.

Jones, E., A. Farina, A. Hastorf, H. Markus, D.T. Miller and R. Scott. 1984. Social Stigma: The Psychology of Marked Relationships. New York: Freeman and Company.

Kantor, M. 1969. "Internal Migration and Mental Illness.” In S. Plog and R. Edgerton, eds., Changing Perspectives in Mental Illness. New York: Holt, Rinehart \& Winston.

Kessler, R.C., K.D. Mickelson and D.R. Williams. 1999. “The Prevalence, Distribution, and Mental Health Correlates of Perceived Discrimination in the United States." Journal of Health and Social Behavior 40: 20830 .

Kessler, R.C., K.D. Mickelson and S. Zhao. 1997. "Patterns and Correlates of Self-help Group Membership in the United States." Social Policy 27: 27-46.

Krieger, N. 1999. "Embodying Inequality: A Review of Concepts, Measures and Methods for Studying Health Consequences of Discrimination." International Journal of Health Services 29: 295-352.

Kuo, W. 1976. "Theories of Migration and Mental Health: An Empirical Testing on Chinese-Americans." Social Science \& Medicine 10: 297-306.

Kuo, W.H. 1995. "Coping with Racial Discrimination: The Case of Asian Americans." Ethnic and Racial Studies 18: 109-27.

Li, X., B. Stanton, X. Chen, X. Fang, D. Lin, R. Mao and J. Wang. 2006. "Heath Indicators and Geographic Mobility among Young Rural-to-Urban Migrants in China." World Health and Population 4: 2-18.

Li, X., B. Stanton, X. Fang, D. Lin, R. Mao, J. Wang, L. Cottrell and C. Harris. 2004. "HIV/STD Risk Behaviors and Perceptions Among Rural-to-urban Migrants in China." AIDS Education and Prevention 16(6): 538-56.

Lin, D., X. Fang, X. Li, J. Xu and H. Liu. 2005. "HIV/AIDS Situation and Prevention Intervention Among Chinese Rural-to-urban Migrants.” Chinese Journal of AIDS\&STD 11(2): 158-60. 
Link, B.G. 1987. "Understanding Labeling Effects in the Area of Mental Disorders: An Assessment of the Effects of Expectations of Rejection.” American Sociological Review 52: 96-112.

Link, B.G. and F.T. Cullen. 1990. "The Labeling Theory of Mental Disorders: A Review of the Evidence.” Research in Community and Mental Health 6: 75-105.

Link, B.G. and F.T. Cullen. 1992. “The Labeling Theory of Mental Disorders: A Review of the Evidence.” In J. Greenley, ed., Mental Illness in Social Context. Greenwich CT: JAI.

Link, B.G., F.T. Cullen, J. Frank and J.F. Wozniak. 1987. "The Social Rejection of Former Mental Patients: Understanding Why Labels Matter.” American Journal of Sociology 92: 1461-500.

Link, B.G. and J.C. Phelan. 2001. On Stigma and Its Public Health Implications. Background paper for the "Stigma and Global Health: Developing a Research Agenda: An International Conference." Bethesda, MD: NIH, September 5-7, 2001.

Liu, A. 2005 (November 10). China's Migrant Workers Pool Dries Up. Retrieved February 28, 2006. <www. chinadaily.com>.

Malcolm, A., P. Aggleton, M. Bronfman, J. Galvao, P. Mane and J. Verrall. 1998. "HIV-related Stigmatization and Discrimination: Its Forms and Contexts." Critical Public Health 8(4): 347-67.

Mays, V.M. and S.D. Cochran. 2001. "Mental Health Correlates of Perceived Discrimination Among Lesbian, Gay, and Bisexual Adults in the United States." American Journal of Public Health 91: 1869-76.

McKelvery, R.S., A.R. Mao and J.A. Webb. 1993. "Premigratory Expectations and Mental Health Symptomaology in a Group of Vietnamese American Youth." Journal of the American Academy of Child and Adolescent Psychiatry 32: 414-18.

McKelvey, R.S. and J.A. Webb. 1996. "Premigratory Expectations and Postmigratory Mental Health Symptoms in Vietnamese Americans." American Academy of Child and Adolescent Psychiatry 35(2): 240-5.

Meyer, I.H. 1995. "Minority Stress and Mental Health in Gay Men." Journal of Health and Social Behavior 36(1): 36-56.

Miritsugu, J. and S. Sue. 1983. “Minority Status as a Stressor.” In R.D. Felner, ed., Preventive Psychology: Theory, Research, and Practice (pp. 162-74). New York: Pergamon.

Noh, S., M. Beiser, V. Kaspar, F. Hou and J. Rummens. 1999. "Discrimination and Emotional Well-being: Perceived Racial Discrimination, Depression, and Coping: A Study of Southeast Asian Refugees in Canada." Journal of Health and Social Behavior 40(3): 193-207.

Oberg, K. 1960. “Cultural Shock: Adjustment to New Cultural Environments.” Practical Anthropology 7: 177.

Papajohn, J. and J. Spiegal. 1971. "The Relationship of Culture Value Orientation Change and Rorschach Indices of Psychological Development." Journal of Cross-cultural Psychology 2: 257.

Parker, S., R.J. Kleiner and B. Needelman. 1969. "Migration and Mental Illness." Social Science \& Medicine 3: 1 .

Pearlin, L.I., A.L. Morton, E.G. Menaghan and J.T. Mullan. 1981. "The Stress Process.” Journal of Health and Social Behavior 22: 337-56.

Pernice, R. and J. Brook. 1996. "The Mental Health Pattern of Migrants: Is there a Euphoric Period Followed by a Mental Health Crisis?” International Journal of Social Psychiatry 42: 18-27.

Qian, W. 1986. Rural-urban Migration and Its Impact on Economic Development in China. Brookfield: VT: Ashgate Publishing Company.

Ren, X.S., B. Amick and D.R. Williams. 1999. "Racial/Ethnic Disparities in Health: The Interplay Between Discrimination and Socioeconomic Status." Ethnicity \& Health 9(2): 151-65.

Rosenberg, M. 1979. Conceiving the Self. New York: Basic Books.

Rosenfield, S. 1997. "Labeling Mental Illness: The Effects of Received Services and Perceived Stigma on Life Satisfaction." American Sociological Review 62: 660-72.

Scombler, G. and A. Hopkins. 1986. "Being Epileptic, Coming to Terms with Stigma." Sociology of Health and Illness 8: 26-43.

Seeborg, M.C., Z. Jin and Y. Zhu. 2000. "The New Rural-to-urban Labor Mobility in China: Causes and Implications.” Journal of Socio-Economics 29: 39-46.

Shen, Q., Y. Lu, C. Hu, X. Deng, H. Gao, X. Huang et al. 1998. "A Preliminary Study of the Mental Health of Young Migrant Workers in Shenzhen.” Psychiatry and Clinical Neurosciences 52: s370-73.

Shi, G.S. 2002 (September 1). "Pay Attention to the Legal Right of Peasant Workers.” People’ Daily (Overseas Edition). 
Sluzki, C.E. 1986. "Migration and Family Conflict.” In R.H. Moos, ed., Coping with Life Crises (pp. 277-88). New York: Plenum.

Stafford, M.C. and R.R. Scott. 1986. “Stigma Deviance and Social Control: Some Conceptual Issues.” In S.C. Ainlay, G. Becker, L.M. Coleman, eds., The Dilemma of Difference (pp. 77-91). New York: Plenum.

Stryker, S. and A. Statham. 1985. "Symbolic Interaction and Role Theory." In G. Lindzey, E. Aronson, eds., Handbook of Social Psychology (pp. 111-178). NY: Random House.

Thompson, V.L. 1996. "Perceived Experiences of Racism as Stressful Life Events.” Community Mental Health 32(3): 223-33.

Tie, P. 1999. "Survey of Risk Factors Among Migrants.” Disease Monitoring 14(6): 229-30.

Wakabayashi, K. 1990. "Migration from Rural to Urban Areas in China.” Developing Econ 28: 503-23.

Walster, E., G.W. Walster and E. Berschied. 1978. Equity: Theory and Research. Boston, MA: Allyn and Bacon.

Wan, G.H. 1995. "Peasant Flood in China: Internal Migration and Its Political Determinants." Third World Quarterly 16(2): 173-96.

Weinberg, S.K. 1966. "The Relevance of the Forms of Isolation to Schizophrenia." International Journal of Social Psychiatry 13: 33.

Weisman, J. 2006 (April 7). “Senate Pact Offers Permits To Most Illegal Immigrants.” Washington Post (p. A01).

Williams, C.L. 1989. "Prevention Programs for Refugees: An Interface for Mental Health and Public Health.” Journal of Primary Prevention 10: 167-86.

Williams, C.L. and J.W. Berry. 1991. "Primary Prevention of Acculturative Stress Among Refugees." The American Psychologist 46: 632-41.

Williams, D.R. and R. Williams-Morris. 2000. "Racism and Mental Health: The African American Experience.” Ethnicity \& Health 5(3/4): 243-68.

Williams D.R., Y. Yu, J.S. Jackson and N.B. Anderson. 1997. "Racial Differences in Physical and Mental Health: Socioeconomic Status, Stress, and Discrimination." Journal of Health Psychology 2: 335-51.

World Bank. 1997. China: 2020-Sharing Rising Incomes, Disparities in China. Washington, DC: The World Bank.

Wu, C. 1997. New Population Problem in the Economic Reform. Beijing: Population Press.

Wu, H.X. and L. Zhou. 1996 (November 10). "Rural-to-urban Migration in China." Asian-Pacific Economic Literature: 54-67.

Wu, X. 2001 (February 14). "Paying Attention to Migrant Crimes.” People’s Daily (p. 9).

Zeng, Y. 1997. "Comparisons of Migratory Population in Wuhan and Other Big Cities. China Population Science 61: 30-5.

Zhang, L. 2001. "Migration and Privatization of Space and Power in Late Socialist China." American Ethnologist 28(1): 179-205.

Zhou, C. 1997. Status and Future of Migrants' Settlements. Unpublished Master's Thesis. Department of Sociology, Nanjing University Graduate School.

Zhou, X. 1999. "Impact of Migration and Urban Experience on Chinese Peasants." Sociology 5: 58-71. 